\title{
Specific System Random Load Forecasts for Nigerian 330 kV 38-Bus Transmission Grid
}

\author{
Melodi A. O. ${ }^{1}$, Adeyanju O. M. ${ }^{2}$ \\ ${ }^{1-2}$ Department of Electrical and Electronics Engineering, Federal University of Technology, Akure, \\ Nigeria \\ Email: ${ }^{1}$ melodiadegoke@yahoo.com; ${ }^{2}$ olatunji.adeyanju@gmail.com
}

\author{
Keywords: Forecast, Nigeria, Operation, Planning, Random load, Transmission
}

\begin{abstract}
This study presents random load forecasts for the Nigerian $330 \mathrm{kV}$ 38-bus transmission grid using a complex trend analysis technique. By considering randomness of monthly load peaks and normal distribution function, yearly load mean and confidence intervals were predicted for the transmission buses from an obtained 10-year historical load population. Also using the proposed algorithm of the mentioned technique, long-term random load forecasts for the transmission system were obtained. The obtained forecasts were compared with results from an earlier prediction model created for the same grid, which comprises a Monte Carlo technique that considers the location's predominant control variables as population and GDP growth; the maximum obtainable error was $24 \%$. The obtained results of forecasts and comparison are applicable for determining effective transmission system planning policy in Nigeria for the forecast period.
\end{abstract}

\section{Introduction}

A current issue in the existing Nigerian power system is planning for expansion. According to [1-3], the existing transmission network (TN) does not meet the requirement for security and reliability. Consideration for load growth is critical to expansion planning [4]. Efficient and adequate future networks may not be achieved if only static load, as in [5], and deterministic time series models are considered for load prediction. Though all forecast models depend on treatment of historical data, obtained time step extremes and mean or most frequent value, based on an appropriate probability distribution, will serve as basis for achieving more adequate system reinforcement's plans [6-9].

Electricity TNs are connected to loads, which are random variables [10] and imply a load flow dynamism under random load scenarios. Consequently, planning becomes more difficult under random loads since the system economic and technical assessments are measures of the system operation and performance [11-13]. However, it is opined that the dynamism of the values of the load variable is bounded by a population (or sample) space, which the planned TN should accommodate without failure of normal operating mode parameters.

On the studied TN, [14] proposed a rigorous probabilistic forecast model for a region, which is juxtaposed for validation of the approach proposed in this study. The probabilistic forecasts study in [14] comprised a specific Monte Carlo technique that considers location predominant driving factors as population and GDP growth. In this study, however, random load forecasts are carried out to obtain an equally robust basis for achieving adequate network expansion plan for Nigerian transmission network and system generating capacity.

Even though random load implies that one cannot predict its value, the distribution may be determined $[15,16]$. In line with [15] and [16], normal probability distribution function (pdf) that represents the historical load variable data is chosen or determined for both approaches. The results obtained from the computation are ten-year random load forecasts and are applied as inputs for investigating the operations and performance of the existing bulk transmission grid of Nigeria using power flow analysis. The existing Nigerian $330 \mathrm{kV}$ TN diagram is presented in Figure 1. It shows 29 bulk load buses, the connections of the power lines, and 12 functional generating stations. The names of the buses are presented in Table 1 . 


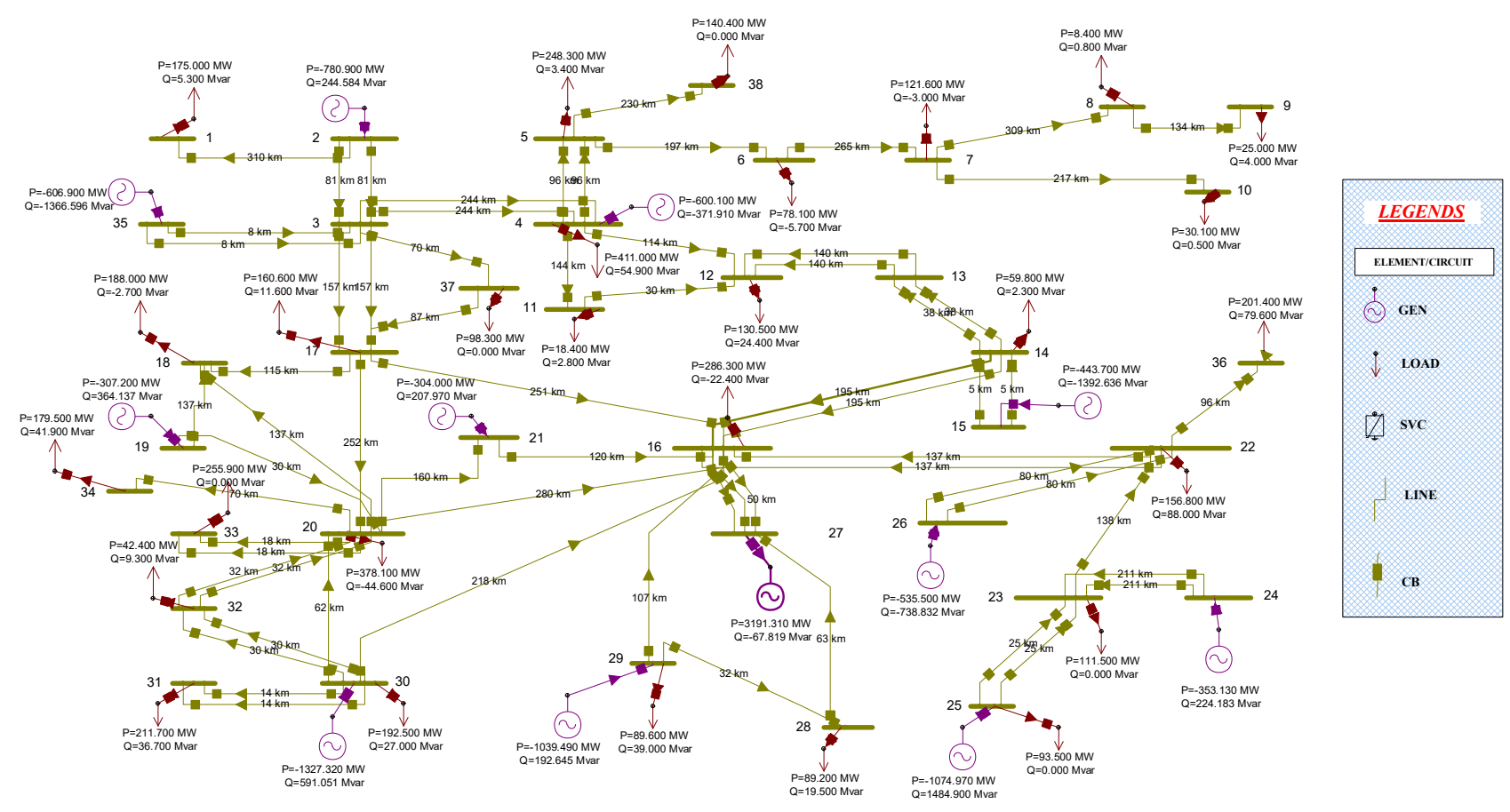

Figure 1: Diagram of existing $330 \mathrm{kV} 38$-bus TN of Nigeria.

\section{Methodology}

Adopting random variable modelling concepts in $[15,16]$, random loads are modeled in this study using available historical yearly load data with appropriate confidence intervals. The annual peak load is considered as the mean for each observed year of a historical period of 2005 to 2014 .

In this concept, the applied load forecast algorithm with consideration for load randomness is formulated and presented as in Equations (1) to (16). According to [15], the probability of a continuous random active load $P_{t}$, measured in $\mathrm{MW}$, falling in an arbitrary interval $(a, b)$ is given in Equation (1).

$$
p\left\{a \leq P_{t} \leq b\right\}=\int_{a}^{b} f\left(P_{t}\right) \cdot d P
$$

where $f\left(P_{t}\right)$ is the probability density function (pdf), $P_{t}$ is the continuous random active load measured in year t, and $a, b$ are arbitrary intervals. As in [16], considering $P_{t}$ to have a normal distribution, then:

$$
P_{t} \sim \mathrm{N}\left(\mu_{P_{t}}, \sigma_{P_{t}}\right) \Rightarrow f\left(P_{t}\right)=\frac{1}{\sqrt{2 \pi \sigma_{P_{t}} P_{t}^{2}}} \exp \left(-\frac{\left(P_{t}-\mu_{\left.P_{t} P_{t}\right)^{2}}\right.}{2 \sigma_{P_{t}} P_{t}{ }^{2}}\right)
$$

where $\mu_{P_{t}}$ and $\sigma_{P_{t}}$ are mean and standard deviation of active load $P_{t}, M W$ respectively.

The expected value or mean, the second moment and the variance or central second moment of the random load are respectively defined and evaluated as in Equations (3) to (5).

$$
\begin{aligned}
& E\left[P_{t}\right]=\mu_{P_{t}}=\int_{a}^{b} P_{t} \cdot f\left(P_{t}\right) \cdot d P \\
& E\left[P_{t}^{2}\right]=\int_{a}^{b} P_{t}^{2} \cdot f\left(P_{t}\right) \cdot d P \\
& \sigma_{P_{t}}{ }^{2}=\int_{a}^{b}\left(P_{t}-\mu_{P_{t}}\right)^{2} \cdot f\left(P_{t}\right) \cdot d P=E\left[P_{t}{ }^{2}\right]-\mu_{P_{t}}{ }^{2}
\end{aligned}
$$

where $\sigma_{P_{t}}{ }^{2}$ is the variance of the active load $P_{t}$.

In this study, the variations of the monthly peak loads $P_{t, m}$ in the year $\mathrm{t}$ is considered as the variation of $P_{t}$. In the historical period, $\sigma_{P_{t}}$ is obtainable from these variations. However, in the 
forecast period the regression of $\sigma_{P_{t}}$ is proposed as an approximate estimate. Consequently, the standard deviation $\sigma_{P_{t}}$ is computed as in Equation (6).

$$
\sigma_{P_{t}}=\left\{\begin{array}{c}
\int_{a}^{b} \sqrt{E\left[P_{t, m}{ }^{2}\right]-\mu_{P_{t, m}}{ }^{2}}, \quad t \in O P \\
\beta t+\sigma_{P_{2005}}, \quad t \in F P
\end{array}\right.
$$

where $O P$ historical data period (2005 to 2014), FP is forecast period (2015 to 2024), and $\beta$ is slope of regression and $\sigma_{P_{2005}}$ is standard deviation in 2005, which is obtained from regression analysis in Excel worksheet.

In order to forecast the determined corridors of loads into the future, a complex time-series forecast was done. Following [17], the formulations are as represented in Equations (7) to (13). The load:

$$
P_{t}=S_{t} I_{t} T_{t}
$$

where $S_{t}$ is the seasonality in the load data set, $I_{t}$ is the irregularity and $T_{t}$ is the trend series

$$
S_{t} I_{t}=\frac{P_{t}}{M A\left(P_{t}\right)}, M A\left(P_{t}\right)=\frac{P_{t}+P_{t-1}}{N}
$$

where $M A\left(P_{t}\right)$ is a 2-period moving average of historic time series load.

In year-step load data series, seasonality is obscured, that is:

$$
S_{t} I_{t} \cong I_{t} \forall S_{t} \approx 1
$$

From obtained values of $I_{t}$ the mean irregularity for a data period of $k$ time-steps (or number of years considered) is obtained using Equation:

$$
I=\frac{\sum I_{t}}{k}=\text { constant }
$$

In order to extract the trend components time-step values, Equation (11) is applied:

$$
T_{t}=\frac{P_{t}}{I}
$$

Using linear regression analysis method, the regression equation for the load's trend values $T_{t}$ is obtained as:

$$
T_{t}=\alpha t+T_{2005}, \quad T_{2005}=\frac{P_{2005}}{I}
$$

where $\alpha$ is slope of the load trend.

Considering Equations (2) to (13), the load forecast model becomes:

$$
P^{f}{ }_{t}=\left\{T_{t} I \pm 3 \sigma_{P_{t}}\right\} \forall P^{f}{ }_{t} \sim N\left(P_{a v \cdot, t}^{f}, \sigma_{P_{t}}\right)
$$

where $P^{f}{ }_{t}$ is the forecasted load in year $t$.

Equation (12) shows that based on a normal pdf, the forecast load for any year can be any value within the bounded space of $T_{t} I \pm 3 \sigma_{P_{t}}$. Also, the minimum, mean and maximum load forecast scenarios are denoted $P^{f}{ }_{\text {min.,t, }}, P^{f}{ }_{a v, t}$, and $P^{f}{ }_{\text {max., } t}$ respectively, and imply that:

$$
P^{f}{ }_{\text {min., },}=T_{t} I-3 \sigma_{P_{t}} ; P^{f}{ }_{a v ., t}=T_{t} I ; P^{f}{ }_{\text {max., }}=T_{t} I+3 \sigma_{P_{t}}
$$

The load forecast algorithm is illustrated in the flowchart that is presented in Figure 2.

The percentage forecast error of $P^{f}{ }_{t}$ compared with aforementioned alternative or earlier probabilistic model $X_{t}$ is evaluated using Equation (15):

$$
e^{f}{ }_{t}=\frac{\left(P_{t}^{f}-X_{t}\right)}{X_{t}} * 100 \%
$$

Where $X_{t}$ is obtained forecast values in [14] and was based on Monte Carlo technique.

Summarily, the obtained forecast using this algorithm is compared to the one obtained in [14] using percentage mean (absolute) error (PME):

$$
P M E_{f p}=\frac{\sum_{t}^{f p} e^{f} t}{f p}
$$

Where $f p$ forecast period $(f p=10)$. 
The values of $e^{f}{ }_{t}$ and $P M E_{f p}$ for the two models were evaluated for the respective year step load boundaries and means.

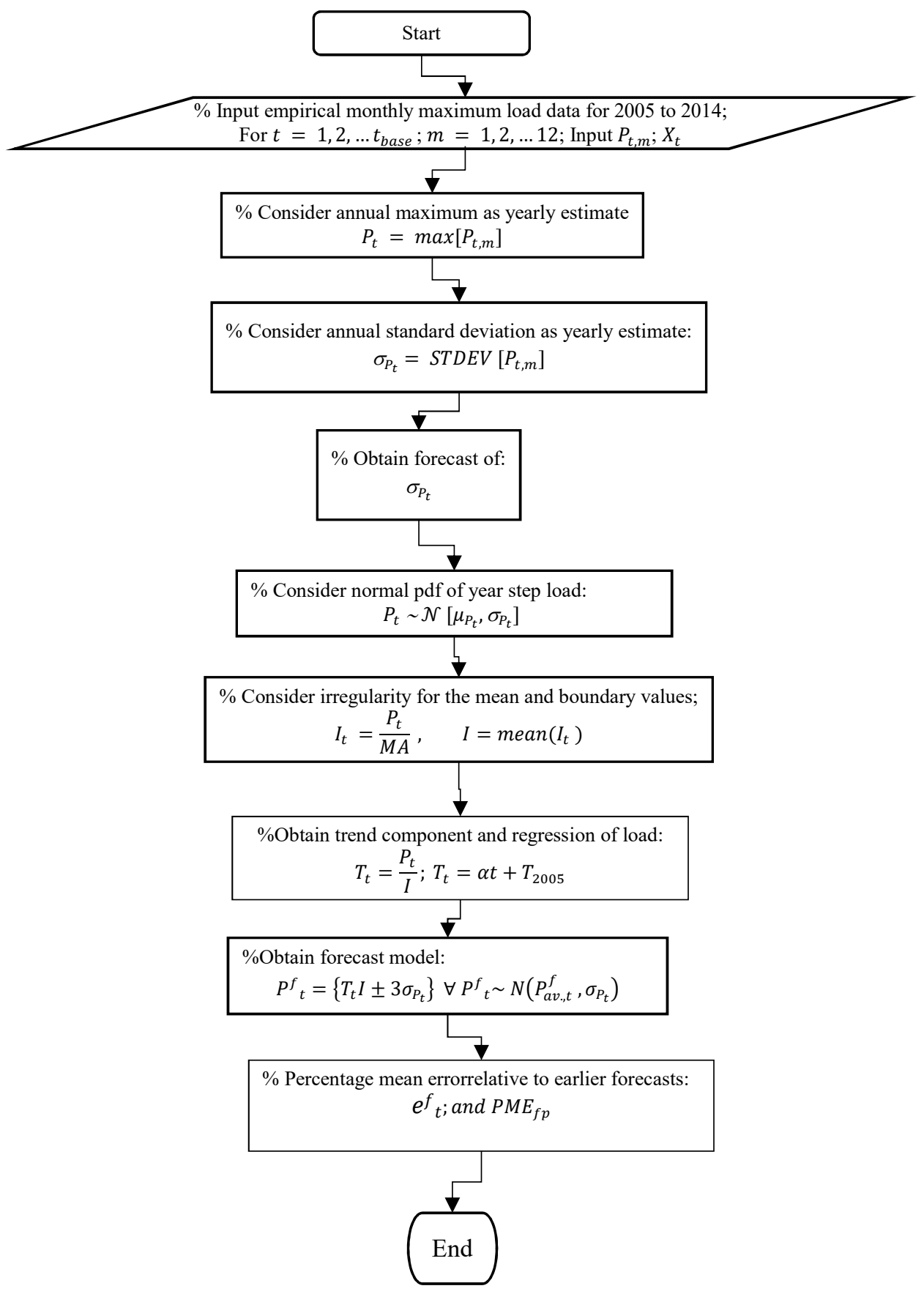

Figure 2: Flowchart of Forecast Algorithm for the Nigerian TN.

\section{Results and discussion}

The obtained time series standard deviations of historical load, using the first option of Equation 6 , is presented in Table 1 for selected transmission grid (TG) buses. These values show some variability that suggested a need for adopting regression equation (second option in Equation 6) to obtain usable values for the forecast period's year levels. This variability in year-level standard deviations of selected buses could imply a condition where the system was not in its full capacity to serve most of the connected loads.

The obtained values from standard deviations regressions for the selected TG buses were applied in Equation 12 to simultaneously obtain the year step pdfs and cdfs as well as the minimum, mean and maximum forecast loads. Obtained normal pdf and cdf of load for a sample load bus are 
presented in Figure 3. This bus, denoted bus 4, is a transmission station (TS) in the north region of the transmission grid and country. The year step probabilistic mean and extremes forecast values are shown in Table 2 for selected buses.

The pdf and cdf in Figure 3 represent a corridor of expected random loads with varying probabilities for the base year. The least probable, the most likely, and the probable maximum forecasts, that is, probabilistic minimum, mean and maximum load values were approximately 411 MW, $550 \mathrm{MW}$ and $689 \mathrm{MW}$ respectively.

Table 1: Obtained standard deviations of historical load for selected buses in year-levels.

\begin{tabular}{|c|c|c|c|c|c|c|c|c|c|c|c|}
\hline \multirow{2}{*}{ BUS NAME } & \multirow{2}{*}{ BUS NO } & \multicolumn{9}{|c|}{ OP } & $\mathbf{2 0 1 0}$ \\
\cline { 3 - 11 } & & $\mathbf{2 0 0 5}$ & $\mathbf{2 0 0 6}$ & $\mathbf{2 0 0 7}$ & $\mathbf{2 0 0 8}$ & $\mathbf{2 0 0 9}$ & $\mathbf{2 0 1 0}$ & $\mathbf{2 0 1 1}$ & $\mathbf{2 0 1 2}$ & $\mathbf{2 0 1 3}$ & $\mathbf{2 0 1 4}$ \\
\hline SHI & 4 & 6.4 & 6.1 & 11.8 & 21.9 & 21.6 & 59.1 & 40.8 & 28.4 & 6.1 & 46.4 \\
\hline KAT & 11 & 0.3 & 0.8 & 0.4 & 0.3 & 0.9 & 0.1 & 0.7 & 0.2 & 0.1 & 0.3 \\
\hline JEB & 3 & 2.9 & 4.1 & 11.3 & 0.6 & 1 & 1.4 & 1.3 & 2.6 & 1.2 & 0.5 \\
\hline KAD & 5 & 8 & 23.3 & 40.9 & 34.6 & 33.6 & 18.7 & 84.9 & 43.5 & 18.6 & 55.2 \\
\hline KAN & 38 & 6 & 24.5 & 14.4 & 46.4 & 16.6 & 13.3 & 19.6 & 44.6 & 40.2 & 30.9 \\
\hline JOS & 6 & 10 & 16.9 & 23.6 & 3.6 & 20 & 12.2 & 11.5 & 9.4 & 3.8 & 6.3 \\
\hline GOM & 7 & 43.5 & 24.8 & 50.1 & 30 & 21.4 & 14.6 & 17.4 & 14.4 & 29.4 & 10.1 \\
\hline YOL & 10 & 4.1 & 1.6 & 28.6 & 8.3 & 4.9 & 2.9 & 2.5 & 7.3 & 8.4 & 8 \\
\hline AKA & 33 & 46 & 31.6 & 27 & 62.8 & 40.7 & 18.9 & 28.4 & 26.3 & 33 & 28 \\
\hline EGB & 30 & 30 & 24.9 & 26.8 & 29.4 & 35.5 & 23.7 & 36.7 & 15.3 & 28.9 & 20.8 \\
\hline AJA & 31 & 2 & 42.8 & 4.9 & 43.7 & 32 & 16.3 & 12.6 & 22.4 & 14.9 & 40.8 \\
\hline IKE & 20 & 2 & 40 & 16.2 & 72.4 & 32.9 & 11.8 & 69.3 & 9 & 87 & 56.6 \\
\hline OSO & 17 & 4.7 & 1.9 & 9.6 & 12.5 & 18.7 & 35.5 & 16 & 31.3 & 8.7 & 45.5 \\
\hline AJA & 14 & 6 & 12 & 43 & 30.5 & 1.5 & 10.2 & 2.8 & 2.1 & 3.2 & 6.7 \\
\hline NEW & 36 & 2 & 20.3 & 44.2 & 38.7 & 25.1 & 12 & 14.4 & 12.4 & 10 & 10.2 \\
\hline ONI & 22 & 3 & 3.5 & 3.7 & 17.3 & 26.1 & 40.2 & 18.2 & 43.4 & 57.9 & 92.1 \\
\hline ALA & 24 & 0.8 & 18.3 & 17.9 & 15.9 & 30.5 & 34.4 & 9.7 & 19.6 & 19.5 & 76.2 \\
\hline AFA & 25 & 1.7 & 1.9 & 1.6 & 6 & 20.4 & 28.9 & 6.2 & 6 & 66.3 & 63.2 \\
\hline GWA & 12 & 2.4 & 4.1 & 4.1 & 4.1 & 4.1 & 4.9 & 4.1 & 4.1 & 5.2 & 14.4 \\
\hline DAM & 8 & 0.2 & 0.2 & 0.2 & 0.2 & 0.2 & 0.2 & 0.2 & 0.3 & 0.2 & 0.7 \\
\hline
\end{tabular}

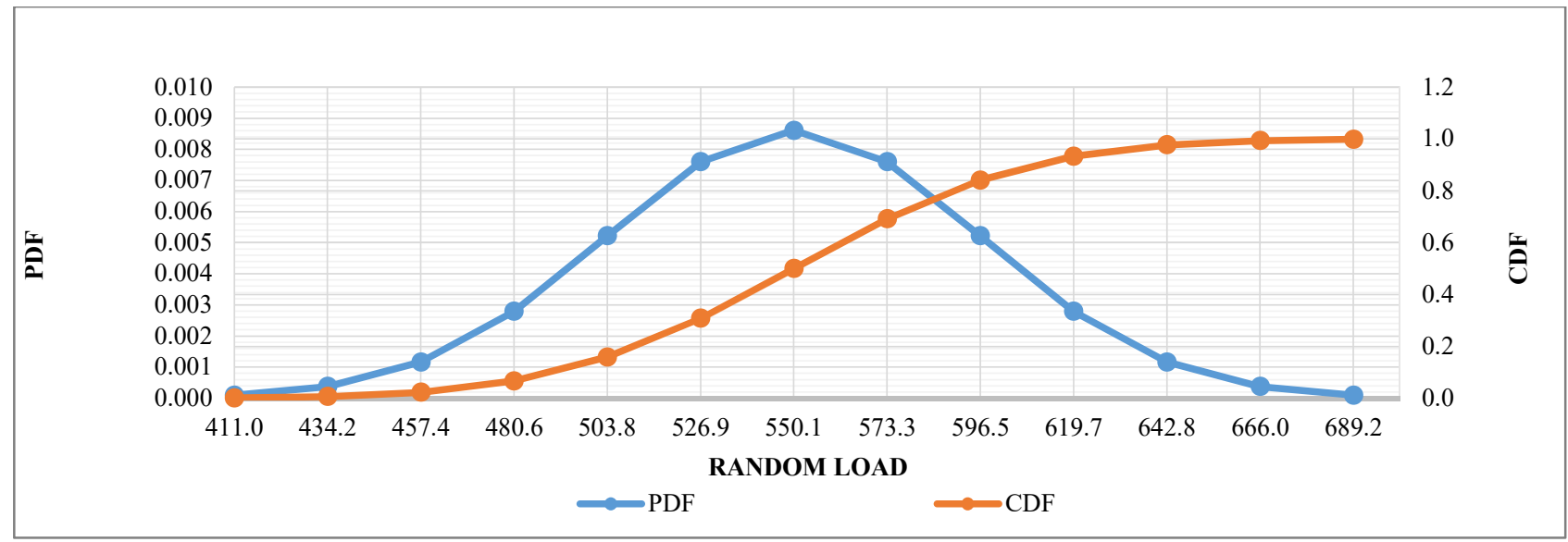

Figure 3: Base-year pdf and cdf for TS bus 4 in 2014.

Table 2: $P^{f}{ }_{t}$ values for selected buses under minimum, mean and maximum loading scenarios.

\begin{tabular}{|c|c|c|c|c|c|c|c|c|c|c|c|c|c|c|c|}
\hline & \multicolumn{3}{|c|}{$2016(\mathrm{P}, \mathrm{MW})$} & \multicolumn{3}{|c|}{$2018(\mathrm{P}, \mathrm{MW})$} & \multicolumn{3}{|c|}{$2020(\mathrm{P}, \mathrm{MW})$} & \multicolumn{3}{|c|}{$2022(\mathrm{P}, \mathrm{MW})$} & \multicolumn{3}{|c|}{$2024(\mathrm{P}, \mathrm{MW})$} \\
\hline & Min & Mean & Max & Min & Mean & Max & Min & Mean & Max & Min & Mean & Max & Min & Mean & Max \\
\hline SHIRORO & 519.36 & 661.35 & 773.70 & 593.10 & 753.83 & 890.85 & 666.84 & 846.31 & 1008.01 & 740.58 & 938.80 & 1125.16 & 814.31 & 1031.28 & 1242.31 \\
\hline KATANPE & 19.33 & 21.11 & 21.18 & 21.39 & 23.18 & 23.33 & 23.44 & 25.25 & 25.48 & 25.50 & 27.32 & 27.64 & 27.56 & 29.39 & 29.79 \\
\hline JEBBA & 29.89 & 35.87 & 40.15 & 35.30 & 42.26 & 47.84 & 40.72 & 48.64 & 55.54 & 46.14 & 55.03 & 63.23 & 51.56 & 61.41 & 70.93 \\
\hline KANO & 225.57 & 420.72 & 577.25 & 248.84 & 459.89 & 649.10 & 272.12 & 499.07 & 720.95 & 295.39 & 538.25 & 792.80 & 318.67 & 577.42 & 864.65 \\
\hline KADUNA & 240.26 & 370.08 & 499.90 & 256.55 & 399.88 & 543.21 & 272.84 & 429.68 & 586.52 & 289.12 & 459.48 & 629.84 & 305.41 & 489.28 & 673.15 \\
\hline JOS & 72.42 & 128.95 & 286.84 & 72.86 & 132.40 & 313.18 & 73.30 & 135.86 & 339.52 & 73.74 & 139.32 & 365.86 & 74.19 & 142.77 & 392.20 \\
\hline GOMBE & 125.77 & 196.62 & 319.36 & 127.03 & 200.28 & 351.08 & 128.29 & 203.93 & 382.79 & 129.54 & 207.58 & 414.51 & 130.80 & 211.24 & 446.22 \\
\hline EGBIN & 150.11 & 249.25 & 327.30 & 155.46 & 256.64 & 332.00 & 160.81 & 264.03 & 336.71 & 166.16 & 271.42 & 341.41 & 171.51 & 278.81 & 346.12 \\
\hline AJA & 213.27 & 316.57 & 411.93 & 227.02 & 341.03 & 453.36 & 240.78 & 365.50 & 494.78 & 254.53 & 389.96 & 536.21 & 268.28 & 414.43 & 577.63 \\
\hline IKEJA-WEST & 251.80 & 563.33 & 746.81 & 276.11 & 578.38 & 776.43 & 300.43 & 593.43 & 806.05 & 324.74 & 608.48 & 835.67 & 349.05 & 623.52 & 865.28 \\
\hline OSOGBO & 235.20 & 351.66 & 471.77 & 246.83 & 384.16 & 524.40 & 258.46 & 416.65 & 577.04 & 270.08 & 449.15 & 629.67 & 281.71 & 481.64 & 682.30 \\
\hline AJAOKUTA & 63.38 & 95.66 & 138.13 & 62.83 & 96.48 & 143.65 & 62.27 & 97.30 & 149.18 & 61.72 & 98.13 & 154.70 & 61.16 & 98.95 & 160.22 \\
\hline NEW-HAVEN & 224.99 & 274.12 & 310.27 & 239.56 & 287.06 & 322.92 & 254.12 & 299.99 & 335.57 & 268.68 & 312.93 & 348.23 & 283.24 & 325.86 & 360.88 \\
\hline ONITSHA & 189.14 & 444.40 & 699.66 & 201.16 & 507.60 & 814.04 & 213.19 & 570.80 & 928.41 & 225.21 & 634.00 & 1042.79 & 237.23 & 697.20 & 1157.17 \\
\hline ALAOJI & 318.32 & 392.28 & 538.70 & 338.60 & 415.82 & 588.33 & 358.88 & 439.37 & 637.97 & 379.16 & 462.91 & 687.60 & 399.43 & 486.46 & 737.24 \\
\hline AFAM & 111.80 & 265.73 & 445.46 & 115.52 & 301.23 & 519.29 & 119.25 & 336.73 & 593.11 & 122.98 & 372.23 & 666.94 & 126.70 & 407.74 & 740.77 \\
\hline GWAGWALADA & 121.57 & 151.61 & 173.12 & 124.95 & 159.09 & 186.40 & 128.34 & 166.57 & 199.67 & 131.72 & 174.05 & 212.95 & 135.11 & 181.52 & 226.23 \\
\hline DAMATURU & 8.59 & 10.06 & 11.46 & 8.70 & 10.40 & 12.00 & 8.82 & 10.74 & 12.53 & 8.93 & 11.07 & 13.06 & 9.04 & 11.41 & 13.59 \\
\hline
\end{tabular}


The results of Table 2 and for other TG buses were summarized to depict the probabilistic load forecast range and mean values for the entire forecast period (that is, not just for a year level). The obtained summaries include Figures 4 and 5, which relate these values to the regional location of the TG buses. The regions are north $(\mathrm{N})$, west (W), east (E), and south (S). Figure 4 shows that forecast loads can vary randomly within significant ranges at TG buses $22(\mathrm{E}), 4(\mathrm{~N}), 1(\mathrm{~N}), 38(\mathrm{~N})$, 5-7 (N), $10(\mathrm{~N}), 25(\mathrm{~S}), 33(\mathrm{~W}), 31(\mathrm{~W}), 20(\mathrm{~W}), 17(\mathrm{~W}), 37(\mathrm{~W}), 18(\mathrm{~W})$ and $16(\mathrm{~W})$. This situation indicate a need to critically determine the adequacy of existing or base year TG capacity in the forecast period. Figure 5 depicts the forecast randomness range for each region and the whole grid. The TG load is expected to randomly vary between $4.7 \mathrm{GW}$ and $13.8 \mathrm{GW}$. The regions with the highest forecast randomness range and peaks are the north $(\mathrm{N})$ and west $(\mathrm{W})$ with optimistic extremes reaching approximately $5.1 \mathrm{GW}$ and $5.3 \mathrm{GW}$ respectively; the lowest is south (S) region, with probable peak incidence of approximately $1 \mathrm{GW}$. These values are just about the size of the existing base year generating capacity. The impact of these values would be TG planning for adequate capacity on the long term.

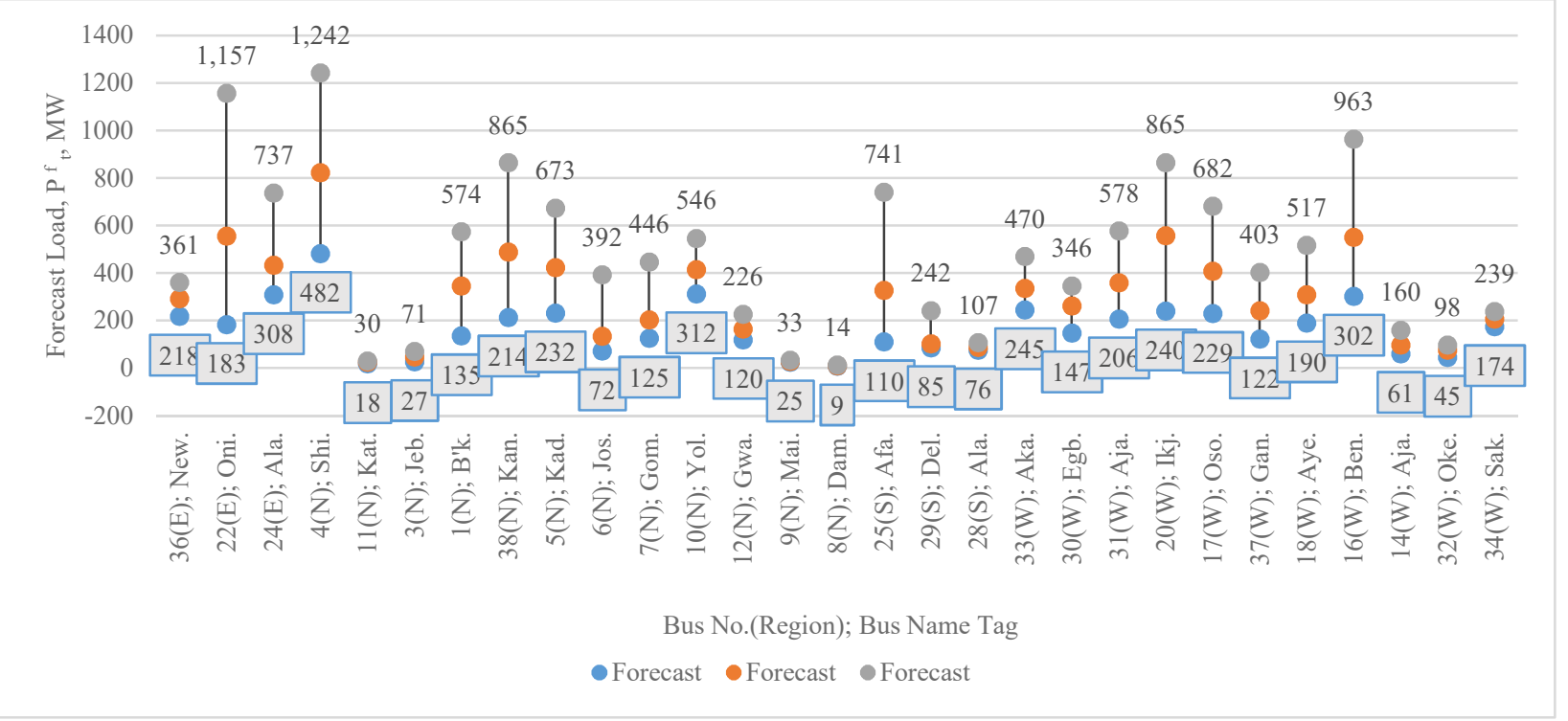

Figure 4: Probabilistic Forecast Minimum, Mean, and Maximum at each T.S in the Forecast Period.

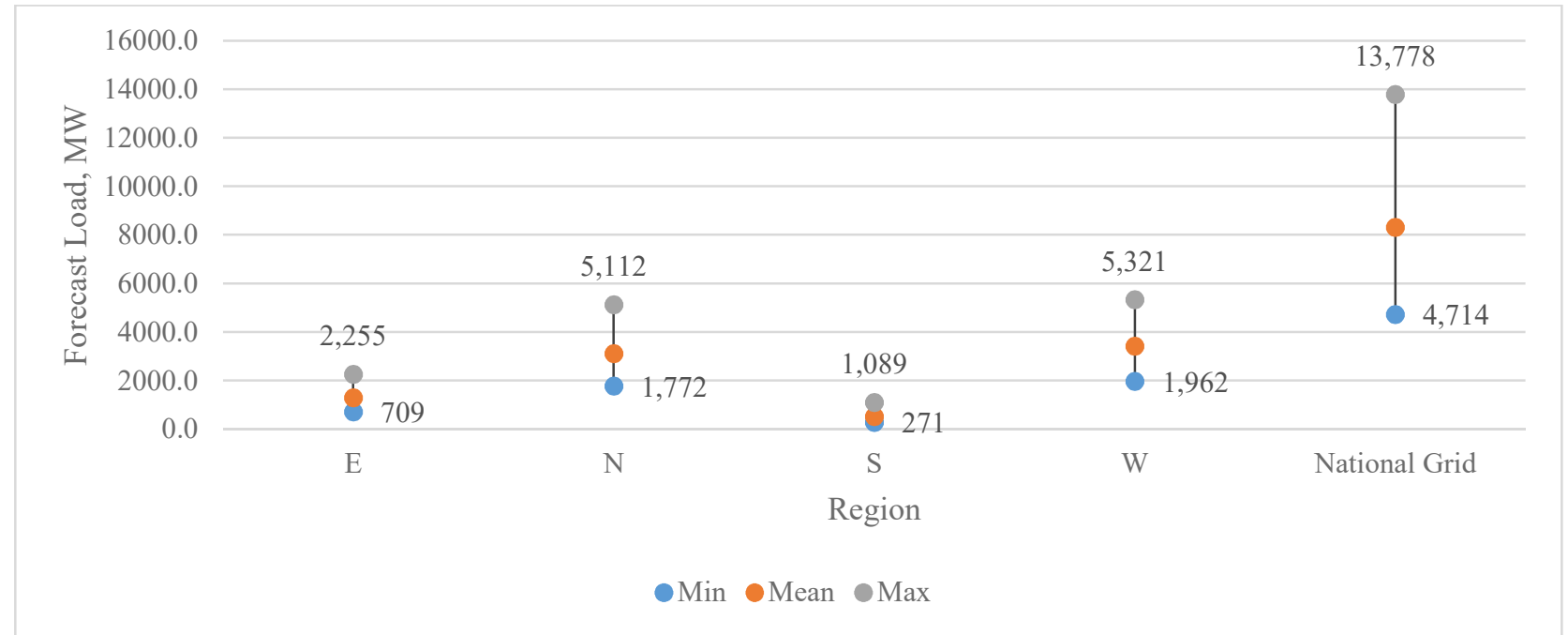

Figure 5: Probabilistic Forecast Minimum, Mean, and Maximum for each Region and the TG in the Forecast Period.

The probabilistic load forecast error obtained after being compared with an alternative existing model is presented in Figure 6. 


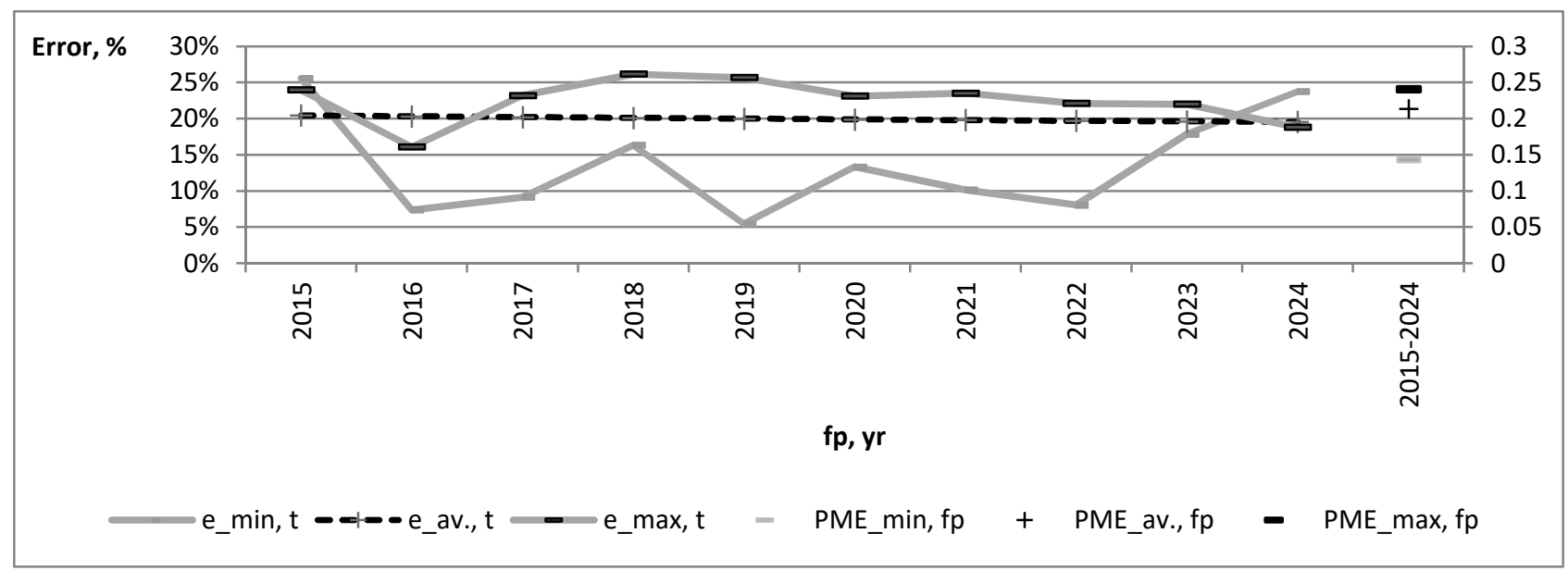

Figure 6: Annual probabilistic load forecast error compared with an existing model.

Figure 6 shows that the 2015-2024 percentage mean forecast error obtained for minimum, mean and maximum forecast loads relative to an alternative Monte-Carlo (MC) model for the Nigerian grid were $14 \%, 21 \%$ and $24 \%$ respectively. This gives an average error factor of approximately 0.2 that should be applied in order to obtain relative conversion of the earlier MC model to the model applied for the forecasts in this paper. This implied that the technique would produce a more optimistic maximum forecast load for the forecast period, which should be considered in system planning.

\section{Conclusion}

Probabilistic long term load forecast has been carried out for Nigerian TG using proposed system specific algorithm. From the analyses of results, the following major conclusions are made. Firstly, the Nigeria TG exhibits a randomly varying load with specific year step extremes and mean. Secondly, the forecast load from 2015 to 2024 would vary randomly between $4.7 \mathrm{GW}$ to $13.8 \mathrm{GW}$, which significantly exceeds existing generating capacity. Thirdly, the existing TG has never been loaded within this range, suggesting a critical need to urgently investigate the need for Nigeria's TG expansion planning, especially the regional links. Fourthly, the regions with the highest forecast randomness range and peaks are the north $(\mathrm{N})$ and west $(\mathrm{W})$ with a combined optimistic value of approximately $10.4 \mathrm{GW}(75.4 \%)$; whereas the conventional primary sources of fossil fuels for developing significant thermal generating stations are in the south region. Consequently, the adequacy of S-N and S-W links would be very critical and be evaluated for adequacy. Finally, the applied forecast algorithm compares with an earlier MC based technique with an average $20 \%$ error, raising the possible optimistic load usable for adequate system planning and reinforcement design. In line with these results of forecasts and comparison, adequate transmission system reinforcement design and implementation is recommended to mitigate power supply problems in the forecast period.

This study is supported by USAID/PEER

\section{References}

[1] A. Agbo, "Ending the Power Nightmare.," Tell Magazine, Lagos, 2002.

[2] A. S. A. Bada, "Status and Opportunities in Transmission Company of Nigeria," Presidential Task force on Power, pp. 1-21, 10 January 2011.

[3] A. Sambo, "Matching Electricity Supply with Demand in Nigeria.," in National Workshop on the Participation of State Governments in the Power Sector, Abuja, 2008. 
[4] G. Drayton, M. McCoy, M. Pereira, E. Cazalet, M. Johannis and D. Phillips, "Transmission Expansion Planning In The Western Interconnection - The Planning Process and the Analytical Tools That Will Be Needed to do the Job," IEEE_final_draft_dwp, Portland, 2004.

[5] A. K. Mishra, P. Walde, D. Rai and S. Rafiullah, "Future of Coordinated Transmission Expansion \& Planning Interconnected Indian Power System," International Journal of Electronic and Electrical Engineering, vol. 7, no. 5, pp. 437-442, 2014.

[6] W. Simpson and D. Gotham, "Standard Approaches to Load Forecasting and Review of Manitoba Hydro Load Forecast for Needs For and Alternatives To (NFAT)," University of Manitoba, Manitoba, 2013.

[7] K. A. Cullen, "Data, Forecasting Electricity Demand using Regression and Monte Carlo Simulation Under Conditions of Insufficient Data," West Virginia University, Virginia, 1999.

[8] R. T. Crow, R. Michael and L. S. Raymond, Forecasting Electricity Sales and Loads: A Handbook for Small Utilities., Washington, D.C.: American Public Power Association, 1981.

[9] S. M. Badran and O. B. Abouelatta, "Forecasting Electrical Load using ANN Combined with Multiple Regression Method," The Research Bulletin of Jordan ACM, vol. 2, no. 2, pp. 52-58, 2010.

[10] A. Zeblah, S. Hadjeri, E. Chatelet and Y. Massim, "Efficient harmony search algorithm for multi-stages scheduling problem for power systems degradation," Springer-Verlag, vol. 92, no. 3, pp. 87-97, 2010.

[11] M. O. Buygi, G. Balzer, H. M. Shanechi and M. Shahidehpour, "Market-based Transmission Expansion Planning," IEEE Transaction on Power System, vol. 19, no. 4, pp. 2060-2067, November 2004.

[12] California ISO, "Transmission Economic Assessment Methodology," California Independent System Operator, California, 2004.

[13] BC Hydro, "Load and Market Forecasting Energy Planning and Economic Development," BC Hydro, British Columbia, 2012.

[14] A. O. Melodi, J. A. Momoh and O. M. Adeyanju, "Probabilistic Long Term Load Forecast for Nigerian Bulk Power Transmission System Expansion Planning," in 2016 IEEE PES Power Africa Conference, Livingstone, 2016.

[15] D. Johnson, "Jointly Distributed Random Variables," 12 May 2005. [Online]. Available: http://cnx.org/content/m11248/latest.

[16] F. James, Monte Carlo Theory and Practice, vol. 43, Geneva: The Institute of Physics, CERN, 1980, p. 1147-1188.

[17] Jalayer Academy, "Time Series Forcasting in Excel," 18 April 2013. [Online]. Available: https://www.youtube.com/watch?v=gHdYEZA50KE. [Accessed 08 July 2015]. 